\title{
Post-Traumatic Right Lumbar Abscess as First Manifestation of Perforated Right Colon Cancer - A Case Report
}

\author{
Anna Rossetto $^{\mathrm{a}}$ Franz Cerato $^{\mathrm{a}}$ Carla Cedolini $^{\mathrm{a}}$ \\ Maria Concetta Arena ${ }^{\mathrm{b}}$ Vittorio Bresadola ${ }^{\mathrm{a}}$ \\ Giovanni Terrosu ${ }^{\mathrm{a}}$ \\ aDepartment of Surgery and Transplantation, University Hospital of Udine, and \\ ${ }^{\text {bDepartment }}$ of Radiology, AOSMM of Udine, Udine, Italy
}

\section{Key Words}

Perforated colon carcinoma - Abscess - Inferior lumbar triangle

\begin{abstract}
Besides most common signs and symptoms suggesting a colic cancer, sometimes the clinical presentation can be difficult. Extra-abdominal abscess as a first sign of perforated colon carcinoma is a very unusual finding. We report a case of an old male patient, in bad general condition, with a post-traumatic finding of right lumbar abscess. After the percutaneous drainage with discharge of fecal material and a postponed explorative laparotomy, we discovered a perforated right colon carcinoma with a covered perforation affecting the duodenum wall and spreading to the hepatic bed and over to the back lumbar muscular wall. Because of the diffusion of the tumor, the patient was treated with palliative surgery with duodenum suture, right colon segment resection and subsequent ileocolic anastomosis with an uneventful postoperative course. The patient died 2 months later because of neoplastic cachexia.
\end{abstract}

\section{Introduction}

Extra-abdominal abscess as a first sign of a perforated colon carcinoma is a very unusual finding. We report a case of a post-traumatic finding of right lumbar abscess mimicking a lumbar hernia as a first sign of perforated colon carcinoma. 


\begin{tabular}{|c|c|c|c|}
\hline $\begin{array}{c}\text { Case Reports in } \\
\text { Ence.ail }\end{array}$ & $\begin{array}{l}\text { Case Rep Oncol 2010;3:40-44 } \\
\text { Dol: 10.1159/000285986 }\end{array}$ & Published online: February 23, 2010 & \begin{tabular}{|l} 
@ 2010 S. Karger AG, Basel \\
ISSN 1662-6575 \\
www.karger.com/cro
\end{tabular} \\
\hline
\end{tabular}

\section{Case Report}

We report the case of a 78-year-old male patient, hospitalized in another department for clinical tests about poor health condition, who came to our attention due to the appearance of a lumbar tumefaction on the right hand side after an accidental fall from the hospital bed.

His anamnesis recorded chronic lymphatic leukemia, $30 \mathrm{~kg}$ loss of weight in 3 years, pain in the right hemithorax and iliac crest, recurring anemia treated with periodic blood transfusions, chronic constipation, recurring urinary infections and prostatic hypertrophy. The patient had slipped receiving a trauma in the right hemithorax. Subsequent X-ray examination revealed 8-9-10 rib fractures unlikely to be present prior to his fall.

The following day a reddened swelling with a maximum diameter of $7 \mathrm{~cm}$ appeared in the right lumbar region. It felt soft and floating. It could be partially reduced and was moderately painful; palpation caused intestinal borborygmus. The ultrasound image showed an elongated formation, not homogenously hypoechoic, containing corpuscular material and vascularization suggesting a lumbar hernia twist between the latissimus dorsi and the oblique muscles.

The patient presented with a temperature of $<38^{\circ} \mathrm{C}$, increased inflammation indexes (CRP $250 \mathrm{mg} / \mathrm{l}$ ), normal defecation and negative abdomen objective exam.

He was given urgent abdominal CT, supine and prone.

On the site of the large tumefaction in the right lumbar area, the exam detected a wide breach in the abdomen wall, $7-8 \mathrm{~cm}$ side to side and $5 \mathrm{~cm}$ cranio-caudal, through which the formation ran as far as the subcutaneous plane. The formation appeared non-homogeneous, with a winding, indented outline, only in part neatly defined. Its contents, partly gaseous, resembled a colon loop with fecal stagnation rather than an abscess.

We also noticed that the prone scanning images suggested pneumoperitoneus starting from the planes crossing the 3 rd inferior part of the homolateral kidney, possibly caused by a covered perforation in that area (fig. 1 and fig. 2).

So we gave the patient local anesthetic and performed draining surgery of the deposit. The incision caused the spilling of fecal material; therefore, we performed toilette and plugging, postponing the explorative laparotomy to the restoration of the electrolytic balance.

Twelve hours later the patient underwent surgery. We found a hard mass in the cecum and the upper length very distended, with a covered perforation affecting the duodenum wall spreading to the hepatic bed and over to the back lumbar muscular wall.

Extemporary histology suggested an adenocarcinoma infiltration. We decided to perform palliative surgery with duodenum suture, right colon segment resection (ileocecal resection) and subsequent ileocolic anastomosis.

The postoperative period was regular; the patient left hospital on the $23 \mathrm{rd}$ postoperative day.

Final histology diagnosed colon adenocarcinoma with lymph node metastasis, ab extrinseco infiltrations in the small intestine wall, duodenum wall and under hepatic tissue (pT4, N1, Mx, G3).

The patient died 2 months later because of neoplastic cachexia.

\section{Discussion}

In order to diagnose a perforated colon carcinoma, besides the typical signs and symptoms, there are some less frequently occurring symptoms such as obstruction with diastatic rupture of the cecum, free perforation, perinephric abscess, colovesical fistula and coloenteric and colovaginal fistula. Abscess formation has been reported to occur in $0.3-0.4 \%$ of colonic carcinomas, but the frequency may be lower because of the recent advance of diagnostic techniques. Most of the perforations related to colorectal cancers are intra-abdominal, while perforated colon carcinoma very rarely presents as abdominal 


\begin{tabular}{|c|c|c|c|}
\hline $\begin{array}{c}\text { Case Reports in } \\
\text { oncelit }\end{array}$ & \begin{tabular}{|l} 
Case Rep Oncol 2010;3:40-44 \\
D0I: 10.1159/000285986
\end{tabular} & Published online: February 23, 2010 & \begin{tabular}{|l} 
@ 2010 S. Karger AG, Basel \\
ISSN 1662-6575 \\
www.karger.com/cro
\end{tabular} \\
\hline
\end{tabular}

wall abscess, groin inflammatory mass, necrotizing fasciitis and subcutaneous abscess [13].

As far as we know by a PubMed research for retroperitoneal abscess, Petit lumbar triangle, right flank abscess, lumbar abscess, posterior abdominal wall abscess, inferior lumbar triangle, and unusual presentation of colon cancer, the literature reports few cases of extra-abdominal abscess as a first sign of real colon cancer, such as gluteal abscess, psoas abscess, abscess in the groin, thigh or anterior abdominal wall [4]. Only a few cases of subcutaneous abscess as a first sign of right colon cancer are described, but none are localized in the right lumbar region. Subcutaneous abscess has been described as an unusual sign of perforated retrocecal appendix [5]. We found a retroperitoneal sigmoid colon perforation presenting with cervical surgical emphysema secondary to abscess rupture through the lumbar triangle of Petit into the posterior paraspinal muscle compartment as a unique report in the English literature [6].

In our experience, the initial diagnostic suspicion was a right lumbar hernia, considering as risk factors the patient's important weight loss and his recent trauma caused by a fall. We think that the colon had its perforation in the retroperitoneal area, letting intestinal material in the locus minoris resistentiae of the Petit triangle. The diagnosis of retroperitoneal abscess can be quite difficult and delays can be fatal since septic complications may suddenly occur.

As for the diagnosis, CT scan should be considered in all cases of abdominal wall/ lumbar region sepsis to detect an intraperitoneal source [5].

Fig. 1. CT scan showing a deposit behind the iliac bone.

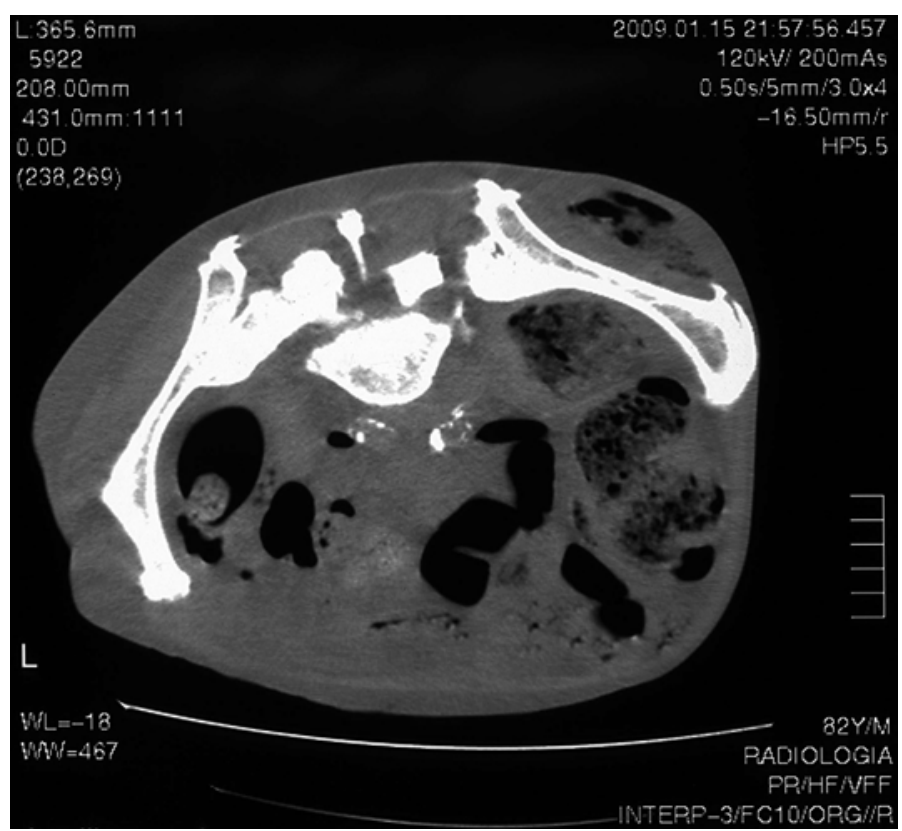




\begin{tabular}{c|l|l|l}
$\begin{array}{c}\text { Cose Reports in } \\
\text { Oncolady }\end{array}$ & $\begin{array}{l}\text { Case Rep Oncol 2010;3:40-44 } \\
\text { D0I: 10.1159/000285986 }\end{array}$ & Published online: February 23, 2010 & $\begin{array}{l}\text { O 2010 S. Karger AG, Basel } \\
\text { ISSN 1662-6575 } \\
\text { www.karger.com/cro }\end{array}$ \\
\hline
\end{tabular}

Fig. 2. CT scan showing perinephric material and subcutaneous air in the posterior wall.

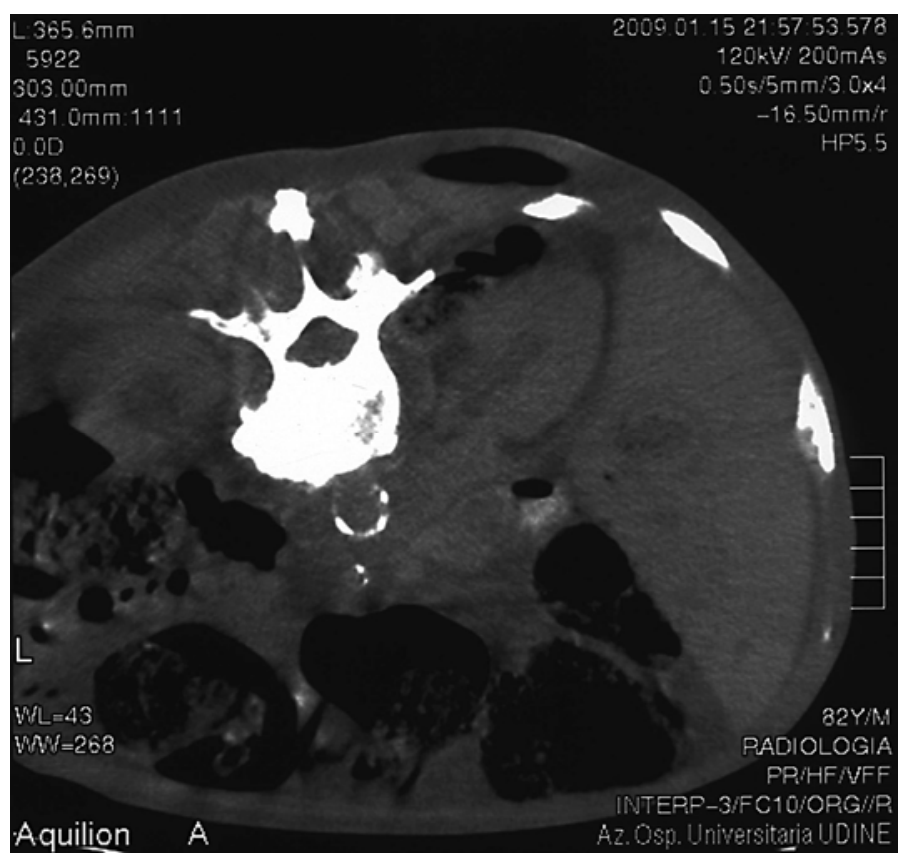




\section{References}

1 Freeman HP, Oluwole SF, Ganepola GA: Unusual presentations of carcinoma of the right colon. Cancer 1979;44:1533-1537.

-2 Marron CD, McArdle GT, Rao M, Sinclair S, Moorehead J: Perforated carcinoma of the caecum presenting as necrotising fasciitis of the abdominal wall, the key to early diagnosis and management. BMC Surg 2006;6:11.

-3 Tsukuda K, Ikeda E, Miyake T, Ishihara Y, Watatani H, Nogami T, et al: Abdominal wall and thigh abscess resulting from the penetration of ascending colon cancer. Acta Med Okayama 2005;59:281-283.

-4 Kobayashi H, Sakurai Y, Shoji M, Nakamura Y, Suganuma M, Imazu H, et al: Psoas abscess and cellulitis of the right gluteal region resulting from carcinoma of the cecum. J Gastroenterol 2001;36:623-628.

5 Fanning DM, Barry M, O'Brien GC, Leahy AL: Perforated retrocaecal appendix presenting as right lumbar abscess. Ir J Med Sci 2007;176:125-128.

-6 Zentner L, Firkin A, House R: Cervical surgical emphysema: rare presentation of a sigmoid colon retroperitoneal perforation with abscess rupture through the lumbar triangle of Petit. Australas Radiol 2007;51:B140-B143. 